\title{
Diels-Alder reaction between naphthalene and $N$-phenylmaleimide under ambient and high pressure conditions
}

\author{
Gulnara G. Iskhakova*, Vladimir D. Kiselev, Elena A. Kashaeva, Lubov’ N. Potapova, \\ Evgeny A. Berdnikov, Dmitry B. Krivolapov, and Igor A. Litvinov \\ A. M. Butlerov Chemical Institute, Kazan State University, Kremlevskaya str.18, 420008 Kazan, \\ Russian Federation \\ E-mail: giskhako@ksu.ru
}

Dedicated to the $70^{\text {th }}$ anniversary of Professor Alexander I. Konovalov

(received 02 Nov 04; accepted 08 Jan 05; published on the web 05 Feb 05)

\begin{abstract}
The rate and equilibrium constants for the Diels-Alder reactions between benzene and naphthalene as dienes and tetracyanoethylene, maleic anhydride and $N$-phenylmaleimide as dienophiles at $25{ }^{\circ} \mathrm{C}$ were estimated from empirical rule. The highest yield of the adduct was predicted for the reaction of naphthalene with $N$-phenylmaleimide. The time of adduct formation in $50 \%$ yield exceeds 30 years. The use of gallium chloride as a catalyst affords the exo-adduct for seven days at room temperature. The rate $\left((2 \pm 0.5) \cdot 10^{-6} \mathrm{~L} \mathrm{~mol}^{-1} \mathrm{~s}^{-1}\right)$ and equilibrium constants $\left(5 \pm 2 \mathrm{~L} \mathrm{~mol}^{-1}\right)$ of this reaction were determined. Under high pressure conditions $(8 \mathrm{kbar})$ reaction occurs with formation of both stereo isomers at $100{ }^{\circ} \mathrm{C}$ during 80 hours.
\end{abstract}

Keywords: Naphthalene, Diels-Alder reaction, catalysis, high pressure

\section{Introduction}

Many dienes, including substituted benzenes and naphthalenes, are known ${ }^{1}$ to form molecular complexes of the $\pi, \pi$-type due to the interaction of the highest occupied $\pi$-orbital of a dienedonor with the lowest unoccupied $\pi$-orbital of a dienophile-acceptor. Numerous examples show that the introduction of donating substituents enhances the stability of $\pi, \pi$-complexes and increases the rate of the Diels-Alder reaction of dienes. ${ }^{2-4}$ Benzene does not react with dienophiles in the Diels-Alder reaction because of the high conjugation energy. Only UV irradiation in the presence of maleic anhydride results in the unstable adduct of [2+2]-addition, which is stabilized by the subsequent [4+2]-addition of the second dienophile molecule. The Diels-Alder reaction with naphthalene does not either occur at room temperature and standard pressure. The adduct was obtained ${ }^{5}$ in $\sim 1 \%$ yield for $24 \mathrm{~h}$ with a great maleic anhydride excess at 
$100{ }^{\circ} \mathrm{C}$. More drastic temperature conditions are unfavorable for the yield of the target adduct, because the process is reversible. Only elevated temperature $\left(100{ }^{\circ} \mathrm{C}\right)$ and pressure $(10-12 \mathrm{kbar})$ make it possible to achieve 90\% yield of the product (adduct of naphthalene with maleic anhydride) ${ }^{6,7}$ The purpose of this work was to estimate the reactivity of simple arenes as dienes in the Diels-Alder reaction, and to use different ways of activation of reactants in this reaction.

\section{Results and Discussion}

It has previously been shown ${ }^{2,3}$ that the quantitative description of the rate of the Diels-Alder reaction between different reagents containing $\mathrm{C}=\mathrm{C}$ bonds at $25{ }^{\circ} \mathrm{C}$ requires data on the ionization potential of the diene $\left(I P_{\mathrm{D}}\right)$, electron affinity energy of the dienophile $\left(E_{\mathrm{A}}\right)$, interatomic $\mathrm{C}(1)-\mathrm{C}(4)$ distance in the diene $\left(R_{1-4}\right)$, and balance of energies of the bond cleavage and formation (reaction enthalpy, $\Delta H_{\text {react }}$ ), equation 1.

$$
\begin{gathered}
\log k_{2}=-28.81+316.3 /\left(I P_{\mathrm{D}}-E_{\mathrm{A}}\right)-69.9 R_{1-4} /\left(I P_{\mathrm{D}}-E_{\mathrm{A}}\right)-0.054 \Delta H_{\text {react }} \\
r=0.972, n=93, s_{0}=0.9,
\end{gathered}
$$

In correlation (1) the $k_{2}$ values are expressed in $\mathrm{L} \mathrm{mol}^{-1} \mathrm{~s}^{-1}, I P_{\mathrm{D}}$ and $E_{A}$ are expressed in $\mathrm{eV}$, $R_{1-4}$ is in $\AA$, and $\Delta H_{\text {react }}$ is $\mathrm{kJ} \mathrm{mol}^{-1}$. This allows one to predict the rates of the Diels-Alder reaction with dienophiles 4-6 for benzene (1) and naphthalene (2). The ionization potentials for benzene $(9.246 \mathrm{eV})$ and naphthalene $(8.14 \mathrm{eV})^{\mathbf{8}}$ and electron affinities energies of dienophiles 46 are known. 2,3 Using the heat of formation, 9 one can calculate the enthalpies of 1,4-addition of the hydrogen molecule to benzene (1) $\left(+23 \pm 4 \mathrm{~kJ} \mathrm{~mol}^{-1}\right)$, naphthalene (2) $\left(-8 \pm 4 \mathrm{~kJ} \mathrm{~mol}^{-1}\right)$, and anthracene (3) $\left(-71 \pm 4 \mathrm{~kJ} \mathrm{~mol}^{-1}\right)$. Comparison of the experimental enthalpies 2,3 of the DielsAlder reactions for anthracene (3) with tetracyanoethylene (4) $\left(-77 \mathrm{~kJ} \mathrm{~mol}^{-1}\right)$, maleic anhydride (5) $\left(-93 \mathrm{~kJ} \mathrm{~mol}^{-1}\right)$, or $N$-phenylmaleimide (6) $\left(-106 \mathrm{~kJ} \mathrm{~mol}^{-1}\right)$ makes it possible to estimate the thermal effects of interaction of these dienophiles with benzene $\left(+17 \pm 4,+1 \pm 4,-12 \pm 4 \mathrm{~kJ} \mathrm{~mol}^{-1}\right)$ and naphthalene $\left(-14 \pm 4,-30 \pm 4,-43 \pm 4 \mathrm{~kJ} \mathrm{~mol}^{-1}\right)$, respectively (Table 1). Additional data on the electron affinity energy 2,3 of tetracyanoethylene $(2.88 \mathrm{eV})$, maleic anhydride $(0.97 \mathrm{eV})$, and $N$ phenylmaleimide $(0.89 \mathrm{eV})$ and interatomic distances in aromatic dienes 1-3 (2.81 $\AA$ ) allow the calculation of logarithms of the rate constants $\left(\log k_{2}\right)$ of these reactions by Eq. (1) (see Table 1). Accepting the entropies of these reactions to be the same ${ }^{3}$ and equal to $-150 \mathrm{~J} \mathrm{~mol}^{-1} \mathrm{~K}^{-1}$, one can estimate the equilibrium constants $\left(K_{\text {eq }}\right)$ (see Table 1 ). The half-life times were calculated for the reactions of the reactants with concentrations of 0.5 and $5 \mathrm{~mol} \mathrm{~L}^{-1}$ (see Table 1). Taking into account the equilibrium constants, the maximum conversion of dienophiles 4-6 in the DielsAlder reaction with benzene is much lower than $0.001 \%$ under these conditions, while for naphthalene this parameter is $\sim 0.001,4$, and $70 \%$ for the reactions with tetracyanoethylene, maleic anhydride, and $N$-phenylmaleimide, respectively. When the pressure is increased to 10-12 
kbar, one can expect an increase in the rate and equilibrium constants by three orders of magnitude. ${ }^{10}$<smiles>c1ccccc1</smiles><smiles>c1ccc2ccccc2c1</smiles><smiles>c1ccc2cc3ccccc3cc2c1</smiles><smiles>N#CC(C#N)=C(C#N)C#N</smiles><smiles>O=C1C=CC(=O)O1</smiles><smiles>O=C1C=CC(=O)N1c1ccccc1</smiles><smiles>O=C1C=CC(=O)N1C1=CC=CCC1</smiles> 
Table 1. Calculated parameters of the Diels-Alder reaction for benzene (1), naphthalene (2), and anthracene (3) with tetracyanoethylene (4), maleic anhydride (5), and $N$-phenylmalenineimide (6): enthalpies of reactions $\left(\Delta H_{\text {react }} / \mathrm{kJ} \mathrm{mol}^{-1}\right)$, rate constants $\left(\log \left(k_{2} / \mathrm{L} \mathrm{mol}^{-1} \mathrm{~s}^{-1}\right)\right)$, equilibrium constants $\left(\log \left(K_{\mathrm{eq}} / \mathrm{L} \mathrm{mol}^{-1}\right)\right)$, half-period of the reaction $\left(\tau_{0.5} / \mathrm{s}\right)$ at the initial concentrations of the reactants 0.5 and $5 \mathrm{~mol} \mathrm{~L}^{-1}$, and equilibrium conversion $\left(\alpha_{\mathrm{eq}}(\%)\right)$ at $25{ }^{\circ} \mathrm{C}$

\begin{tabular}{ccccccc}
\hline Diene & $\begin{array}{c}\text { Dieno- } \\
\text { phile }\end{array}$ & $\Delta H_{\text {react }}$ & $\log k_{2}$ & $\tau_{0.5}$ & $\log K_{\text {eq }}$ & $\alpha_{\text {eq }}$ \\
\hline 1 & 4 & $+17 \pm 4$ & $-10.8 \pm 0.9$ & $9 \cdot 10^{9}$ & $-10.6 \pm 1.0$ & $1 \cdot 10^{-(8 \pm 1)}$ \\
1 & 5 & $+1 \pm 4$ & $-13.9 \pm 0.9$ & $1 \cdot 10^{13}$ & $-7.9 \pm 1.0$ & $6 \cdot 10^{-(6 \pm 0.5)}$ \\
1 & 6 & $-12 \pm 4$ & $-13.7 \pm 0.9$ & $7 \cdot 10^{12}$ & $-5.6 \pm 1.0$ & $(1-3) \cdot 10^{-3}$ \\
2 & 4 & $-14 \pm 4$ & $-5.2 \pm 0.9$ & $2 \cdot 10^{4}$ & $-5.3 \pm 1.0$ & $2 \cdot 10^{-(3 \pm 0.5)}$ \\
2 & 5 & $-30 \pm 4$ & $-10.4 \pm 0.9$ & $3.5 \cdot 10^{9}$ & $-2.5 \pm 1.0$ & $4 \pm 2$ \\
2 & 6 & $-43 \pm 4$ & $-9.9 \pm 0.9$ & $1 \cdot 10^{9}$ & $-0.3 \pm 1.0$ & $70 \pm 20$ \\
3 & 4 & $-77^{*}$ & $0.48^{*}$ & - & $5.5 \pm 1.0$ & - \\
3 & 5 & $-93^{*}$ & $-5.22^{*}$ & - & $8.3 \pm 1.0$ & - \\
3 & 6 & $-106^{*}$ & $-5.14^{*}$ & - & $10.5 \pm 1.0$ & - \\
\hline
\end{tabular}

* Experimental data., ${ }^{2,3}$

Catalysis by Lewis acids makes it possible to increase the reaction rate by five orders of magnitude without changing the equilibrium constant. ${ }^{2,3}$ Since the absolute value of activation enthalpy is much higher than the reaction enthalpy, an increase in the reaction rate constant $\left(k_{2}\right)$ with temperature is sharper than a decrease in the equilibrium constant. However, the $\log K_{\text {eq }}$ value for benzene is very low even in the reaction with $N$-phenylmaleimide $(-5.6 \pm 1.0)$. Thus, for the Diels-Alder reactions involving benzene and $N$-phenylmaleimide in the presence of aluminum or gallium chlorides at $10-12 \mathrm{kbar}$ and $25^{\circ} \mathrm{C}$, one can expect an increase in $k_{2}$ from $2 \cdot 10^{-14}$ to $2 \cdot 10^{-6} \mathrm{~L} \mathrm{~mol}^{-1} \mathrm{~s}^{-1}$ and in $K_{\text {eq }}$ from $2.5 \cdot 10^{-6}$ to $2.5 \cdot 10^{-3} \mathrm{~L} \mathrm{~mol}^{-1}$ with the maximum conversion not higher than $1-2 \%$ for $20-30 \mathrm{~h}$. When the pressure is discharged, the $K_{\text {eq }}$ value again becomes equal to $2.5 \cdot 10^{-6} \mathrm{~L} \mathrm{~mol}^{-1}$ but the rate of adduct decomposition is rather low $\left(7 \cdot 10^{-}\right.$ $9 \mathrm{~s}^{-1}$ ), which may allow one to detect its formation. It is $\mathrm{known}^{2,3}$ that the introduction of donating groups, for example, methyl groups, into positions 1 and 4 of diene and replacement of ethylenic dienophiles by acetylenic dienophiles exert a favorable effect on the kinetic and thermodynamic parameters of the Diels-Alder reaction. This was experimentally confirmed for polymethylnaphthalenes and even polymethylbenzenes. ${ }^{4}$ It is clear that several products of the reactions between benzene and dienophiles with the double bond can much more easily be obtained by the interaction of the corresponding cyclohexadienes with acetylenic dienophiles. However, the affinity of the adducts to decomposition with benzene formation accompanies both these processes. For naphthalene the highest rate is expected in the reaction with tetracyanoethylene (4) but the conversion under standard conditions is so low that adduct formation cannot be detected (see Table 1). The experimental data at elevated temperatures 
indicate a much higher yield of the products in the reaction of naphthalene with $\mathrm{N}$ phenylmaleimide $^{11}$ than that with maleic anhydride, ${ }^{5}$ which agrees with the results of calculations (see Table 1). However, all these reactions do not occur at standard temperature because of very low rates. In this work, we studied the reaction of naphthalene (2) with $\mathrm{N}$ phenylmaleimide (6) at room temperature. According to the presented calculations (see Table 1), the half-life (more than 30 years) is too long for experiment. An extensive material on the kinetic data indicates that the Diels-Alder reaction is accelerated in the presence of Lewis acid., ${ }^{2,3}$ Gallium chloride, which is easily soluble in inert organic solvents, forms a stable $n, v$-complex with many dienophiles, including maleimides. ${ }^{2,3}$ The electron affinity energy of $N$ phenylmaleimide (6) for its transformation into the $n, v$-complex (7) with gallium chloride (Scheme 1) increases from 0.89 to $1.93 \mathrm{eV}{ }^{12}$ The rate of the Diels-Alder reaction between substituted anthracenes and activated dienophile (7) increases by $5 \cdot 10^{4}$ times. ${ }^{13}$ It follows from these data that the rate constant of the reaction of naphthalene with $N$-phenylmaleimide can increase from $1.2 \cdot 10^{-10}$ to $6 \cdot 10^{-6} \mathrm{~L} \mathrm{~mol}^{-1} \mathrm{~s}^{-1}$. The endo- (m.p. $161{ }^{\circ} \mathrm{C}$, with decomp.) and exoadducts (m.p. $172{ }^{\circ} \mathrm{C}$, with decomp.) have recently ${ }^{7}$ been isolated in the reaction of naphthalene with maleic anhydride at $100{ }^{\circ} \mathrm{C}$ and $12 \mathrm{kbar}$ in $\mathrm{CHCl}_{3}$. The chemical shifts in the ${ }^{1} \mathrm{H}$ and ${ }^{13} \mathrm{C}$ NMR spectra differ significantly for the endo- and exo-adducts. ${ }^{7}$ However, the NMR spectra of the adduct obtained in the catalyzed reaction $2+7$ (Scheme 2) indicate the presence of the only one isomer (8 or 9). Exo-isomer 8 with m.p. $206{ }^{\circ} \mathrm{C}$ was obtained ${ }^{11}$ with yield $10 \%$ in the reaction $2+6$ in boiling xylene $\left(140{ }^{\circ} \mathrm{C}\right)$, whereas the adduct obtained in our work had m.p. 206$208{ }^{\circ} \mathrm{C}$ (with decomp.) Earlier ${ }^{14}$ it was by mistake described as endo-isomer on the basis of the incorrect melting point. X-Ray crystal structure investigation of the reaction product shows that this molecule has exo-configuration, corresponding to the isomer 8.

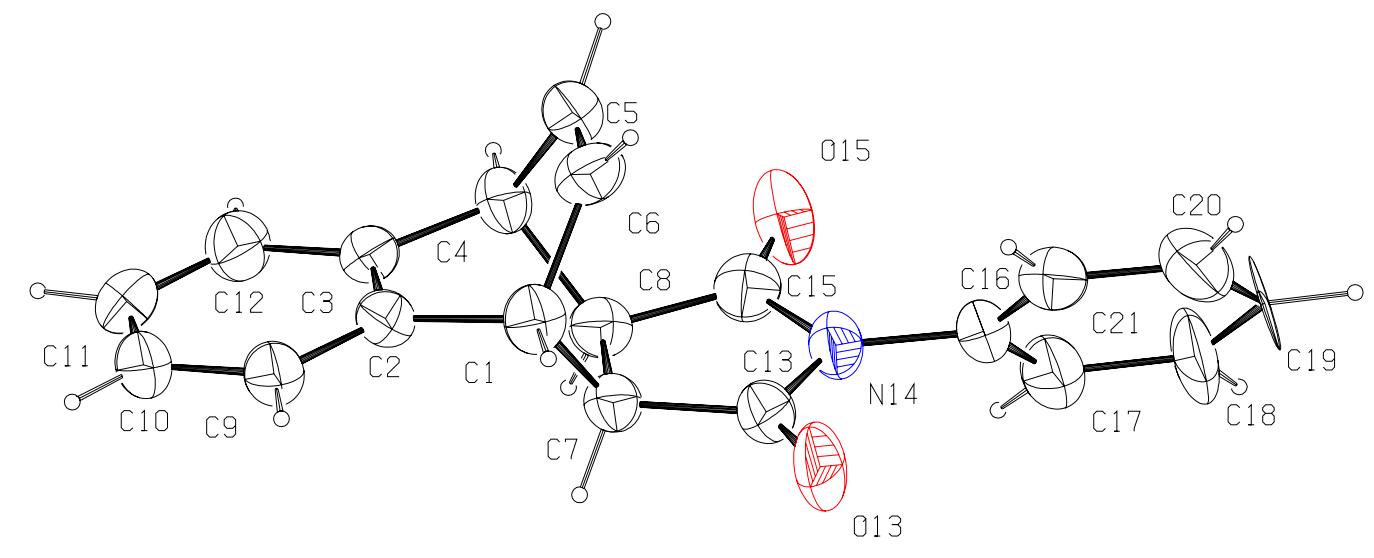

Figure 1. ORTEP drawing of the molecule 8.

Molecule 8 has step-like conformation; five-membered cycle is planar, and nearly parallel to the condensed benzene ring (dihedral angle between these planes is $\left.6.1(2)^{\circ}\right)$. Central bicycle has local symmetry $\mathrm{C}_{3}, 6$-membered cycles in bicyclic system have boat conformation. Phenyl 
substituent at the N14 atom is non coplanar with the plane of 5-membered heterocycle, dihedral angle between these planes is $52.9(2)^{\circ}$. Tetracyclic system of molecule has the local symmetry $\mathrm{C}_{\mathrm{s}}$, geometric parameters of corresponding fragments are equivalent in the range of experimental errors. In general main geometry parameters of the molecule (bond lengths and bond angles) are normal. Crystal packing of this compound may be considered as lamellar, consists of centrosymmetric dimers of molecules, dimers formation by the $\pi-\pi$ interactions between 5 membered heterocycles and condensed benzene ring (Fig.2.). Dihedral angles between planes of these rings are $6.1^{\circ}$, distance between centers of rings is $3.94 \AA$, interplanar distance is $3.44 \AA$.

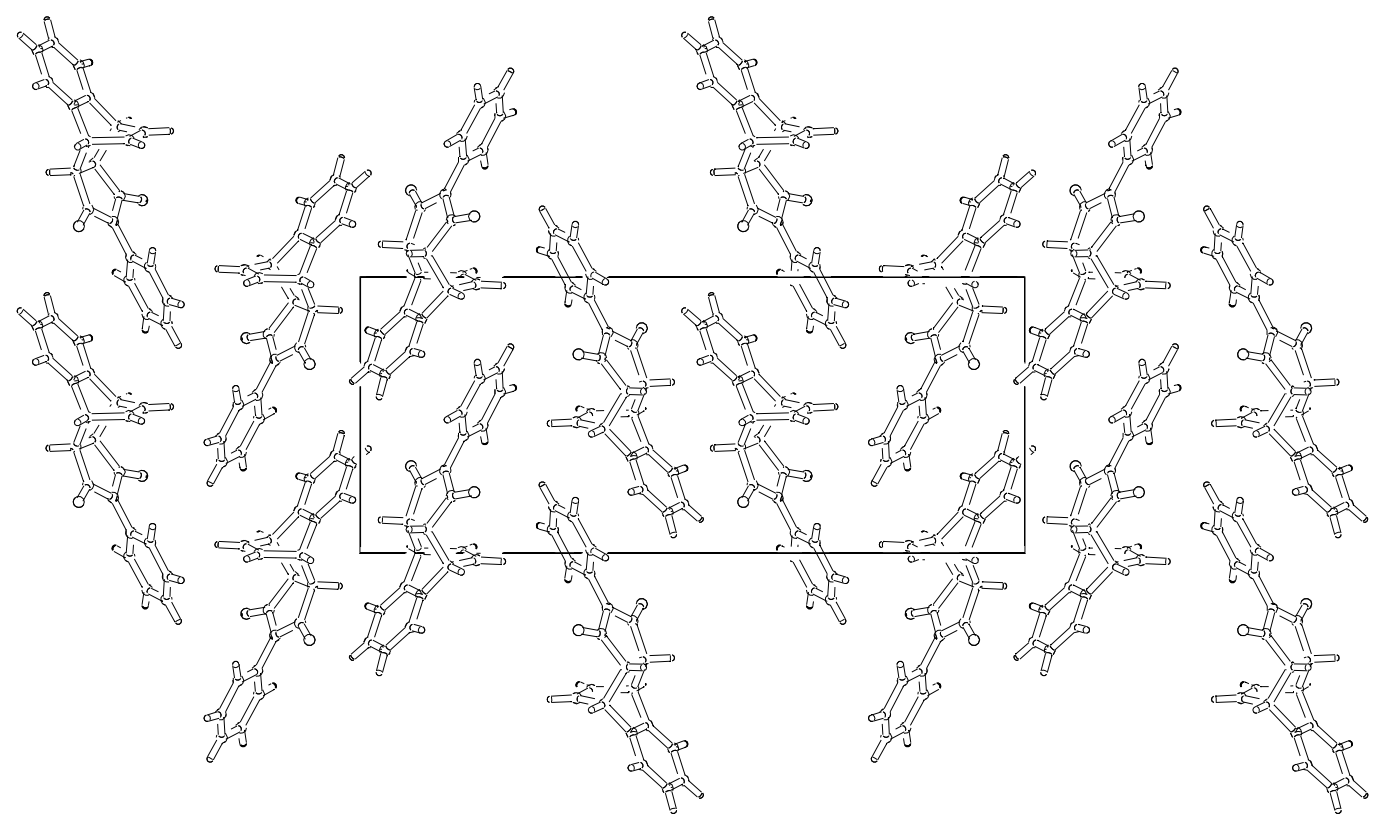

Figure 2. PLUTO drawing of the crystal structure of the compound $\mathbf{8}$. View along XO axe.

The experimental value of the rate constant of the catalyzed reaction at $22 \pm 2{ }^{\circ} \mathrm{C}$ is equal to $(2.0 \pm 0.5) \cdot 10^{-6} \mathrm{~L} \mathrm{~mol}^{-1} \mathrm{~s}^{-1}$, which corresponds satisfactorily to the calculated value $\left(6 \cdot 10^{-6} \mathrm{~L} \mathrm{~mol}^{-1}\right.$ $\mathrm{s}^{-1}$ ). The change in the absorption of the $\pi, \pi$-complex for 24 days (from 0.954 to 0.320 ) made it possible to estimate the equilibrium constant of the catalyzed reaction $\left(5 \pm 2 \mathrm{~L} \mathrm{~mol}^{-1}\right)$.Under high pressure conditions ( $8 \mathrm{kbar}, 100{ }^{\circ} \mathrm{C}, 80$ hours) reaction occurs with formation of both stereo isomers. According to NMR spectra, ratio of endo:exo isomers in reaction mixture was 30:70. 


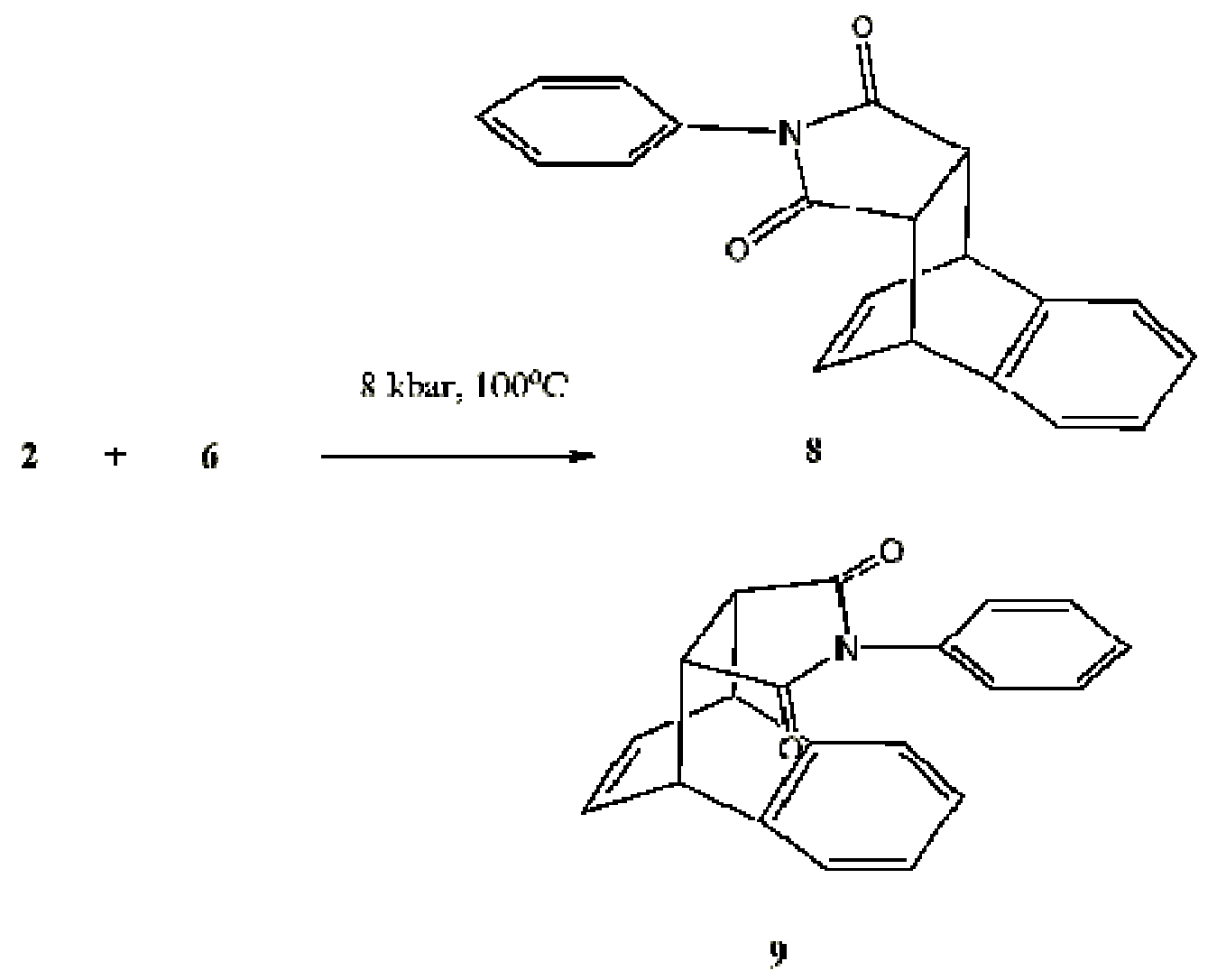

\section{Experimental Section}

General Procedures. ${ }^{1} \mathrm{H}(300 \mathrm{MHz})$ and ${ }^{13} \mathrm{C}(75 \mathrm{MHz})$ NMR spectra were recorded on a Varian Unity-300 instrument in a $\mathrm{CDCl}_{3}$ solution using the signal of the proton of $\mathrm{CHCl}_{3}$, whose traces were in the solution, as an internal standard. The $\delta$ values were calculated relatively to $\mathrm{Me}_{4} \mathrm{Si}$.

Measurement of the reaction rate. A benzene solution of reactants $6\left(0.0458 \mathrm{~mol} \mathrm{~L}^{-1}\right), \mathrm{GaCl}_{3}$ $\left(0.040 \mathrm{~mol} \mathrm{~L}^{-1}\right)$, and $2\left(0.416 \mathrm{~mol} \mathrm{~L}^{-1}\right)$ was prepared. The solution was placed in a quartz cell $(l=$ $1 \mathrm{~cm}$ ), whose upper part was welded (through transient alloys) to a molybdenum glass tube. Dry argon was passed through the cell, and the tube was sealed. At these concentrations and temperature of $22 \pm 2{ }^{\circ} \mathrm{C}$, crystals of the adduct are not precipitated even for 24 days. At an excessive naphthalene concentration $\left(C_{2}\right)$, the current concentration of the $\pi, \pi$-complex $\left(C_{\mathrm{c}}\right)$ between reactants $\mathbf{2}$ and $\mathbf{7}$ is proportional to the current concentration of activated dienophile $\mathbf{7}$ $\left(C_{7}\right)$

$$
c_{\mathrm{c}}=c_{7} K_{\mathrm{c}} c_{2} /\left(1+K_{\mathrm{c}} c_{2}\right)
$$

where $K_{\mathrm{c}}$ is the equilibrium constant of the $\pi, \pi$-complex between reactants 2 and 7 (equation 2). The change in the absorption of the $\pi, \pi$-complex $\left(A_{\mathrm{c}}\right)$ for 24 days (from 0.954 to 0.320 ) made it 
possible to determine the rate constant $\left((2.0 \pm 0.5) \cdot 10^{-6} \mathrm{~L} \mathrm{~mol}^{-1} \mathrm{~s}^{-1}\right)$ from the initial region of the $\ln A_{\mathrm{c}^{-}} t$, and then the equilibrium constant of the catalyzed reaction $\left(5 \pm 2 \mathrm{~L} \mathrm{~mol}^{-1}\right)$ was calculated.

High pressure experiment was carried out in $2 \mathrm{ml}$ Teflon ampoule in a piston cylinder type barostat $^{15}$. The solution of $1.76 \mathrm{M} \mathrm{N}$-phenylmaleimide and 1.93 $\mathrm{M}$ naphthalene in chloroform was placed in Teflon ampoule and kept at $8 \mathrm{kbar}$ at $100{ }^{\circ} \mathrm{C}$ during 80 hours. Under high pressure conditions $(8 \mathrm{kbar})$ reaction occurs with formation of the both stereo isomers at $100{ }^{\circ} \mathrm{C}$ during 80 hours.

X-Ray structure determination. The X-Ray diffraction data for the crystal of (8) were collected on a CAD4 Enraf-Nonius automatic diffractometer using graphite monochromated radiation.

Crystallographic data. The crystals of $8, \mathrm{C}_{20} \mathrm{H}_{15} \mathrm{O}_{2} \mathrm{~N}, \mathrm{M}=301.35$, are monoclinic, space group $\mathrm{P} 2{ }_{1} / \mathrm{n}$, at $298 \mathrm{~K} \mathrm{a}=6.1344(6), \mathrm{b}=24.010(5), \mathrm{c}=10.424(2) \AA, \beta=106.54(5)^{\mathrm{o}}, \mathrm{V}=1471.8(6) \AA^{3}$, $\mathrm{Z}=4, \mathrm{~d}_{\text {calc }}=1.36 \mathrm{~g} \mathrm{~cm}^{-3}, \operatorname{MoK} \alpha(\lambda=0.71073 \AA), \mu=0.82 \mathrm{~cm}^{-1}, \omega / 2 \theta$-scan, 3343 reflections measured, 1420 observed $[\mathrm{I} \geq 2 \sigma(\mathrm{I})], 268$ refined parameters, $\mathrm{R}=0.039 \mathrm{R}_{w}=0.042$.

The stability of crystal and experimental conditions was checked every 2 hours using three control reflections, while the orientation was monitored every 200 reflections by centering two standards. No significant decay was observed. Corrections for Lorentz and polarization effects were applied. Absorption correction was not applied. The structures were solved by direct methods using $\mathrm{SIR}^{\mathbf{1 6}}$ and $\mathrm{MolEN}^{\mathbf{1 7}}$ packages. For the crystals all non-hydrogen atoms were refined anisotropically. H-atoms, located in $\Delta \mathrm{F}$ maps, were refined isotropically at the last cycles. Analysis of intermolecular contacts and drawing of molecular and crystal structures were performed by program PLATON ${ }^{\mathbf{1 8}}$.

Compound characterization. Commercial $N$-phenylmaleimide (6) (Aldrich), benzene (reagent grade), and naphthalene (2) (reagent grade) were used. Chloroform (reagent grade) was purified by known methods ${ }^{19}$.

exo- $N$-Phenyl 2,3-Benzobicyclo[2.2.2]octa-2,5-diene-7,8-dicarboximide (8). Gallium chloride $\left(1.01 \mathrm{~g}, 0.1 \mathrm{~mol}^{*} \mathrm{~L}^{-1}\right)$ was dissolved in anhydrous benzene (reagent grade) containing $N$ phenylmaleimide $\left(1.15 \mathrm{~g}, 0.115 \mathrm{~mol}^{*} \mathrm{~L}^{-1}\right)$, and then naphthalene $\left(12.8 \mathrm{~g}, 1.76 \mathrm{~mol}^{*} \mathrm{~L}^{-1}\right)$ was added. Argon was passed through the resulting solution, and the reactor was tightly closed and left for 7 days at $\sim 20{ }^{\circ} \mathrm{C}$. Already two days after, a precipitate of the adduct complex with gallium chloride $\left(\mathbf{8} \cdot \mathrm{GaCl}_{3}\right)$ began to form. After 7 days, the precipitate was filtered off, powdered, washed with benzene and hexane, and dissolved in $\mathrm{CH}_{2} \mathrm{Cl}_{2}$. Gallium chloride was removed from adduct $\mathbf{8} \cdot \mathrm{GaCl}_{3}$ with aqueous ammonia, and the solution was washed with water and dried with $\mathrm{MgSO}_{4}$. The volume of the solution was brought to $20 \mathrm{~mL}$, and the adduct was precipitated with hexane and dried in vacuo. The yield of pure adduct 8 was $0.6 \mathrm{~g}(30 \%$ calculated per taken imide 6), m.p. $206-208^{\circ} \mathrm{C}$ (with decomp.). Found (\%): C, 79.97; H, 4.95; N, 4.80. $\mathrm{C}_{20} \mathrm{H}_{15} \mathrm{NO}_{2}$. Calculated (\%): C, 79.72; H, 5.02; N, 4.65. ${ }^{1} \mathrm{H}$ NMR, $\delta: 3.16(\mathrm{~m}, 2 \mathrm{H}, \mathrm{H}(7)$, $\mathrm{H}(8))$; 4.60 (m, $2 \mathrm{H}, \mathrm{H}(1), \mathrm{H}(4))$; 6.65 (m, $2 \mathrm{H}, \mathrm{H}(5), \mathrm{H}(6))$; 7.15-7.52 (m, $9 \mathrm{H}, \mathrm{H}$ arom.). ${ }^{13} \mathrm{C}$ NMR, $\delta$ : 42.76 (C(1), C(4)); 47.04 (C(7), C(8)); 124.42, 126.93, 127.09, 129.40, 129.81, 132.46, $134.79,142.61(\mathrm{C}(5), \mathrm{C}(6)$, and $12 \mathrm{C}$ arom.); $177.01(2 \mathrm{C}=\mathrm{O})$. 
From the reaction mixture after high pressure synthesis, using the column chromatography (eluent petroleum ether:ethylacetate 1:6) exo- $N$-phenyl 2,3-Benzobicyclo[2.2.2]octa-2,5-diene7,8-dicarboximide was obtained, with melting point and the other properties the same as described for the catalytic reaction product. Similarly to the adduct of naphthalene with maleic anhydride ${ }^{7}$, exo-isomer was eluted first, and endo-isomer was eluted the last and very hardly.

Endo-isomer was not separated as pure compound. ${ }^{1} \mathrm{H}$ NMR spectra and TLC show the presence of exo -isomer impurity (10\% approximately), the melting point of the crystals is 146 $148{ }^{\circ} \mathrm{C}$

'H NMR, $\delta: 3.25$ (m, 2 H, H(7), H(8)); 4.50 (m, 2 H, H(1), H(4)); 6.43 (m, 2H, arom); 6.72 (m, $2 \mathrm{H}, \mathrm{H}(5), \mathrm{H}(6)) ; 7.15-7.52$ (m, $7 \mathrm{H}, \mathrm{H}$ arom.).

\section{Supplementary Information}

Crystallographic data (excluding structure factors) for the structure 8 reported in this paper has been deposited with the Cambridge Crystallographic Data Centre and has been allocated deposition numbers CCDC 254358. Copies of the data can be obtained, free of charge, on application to CCDC, 12 Union Road, Cambridge CB2 1EZ, UK [fax: +44(0) 1223-336033 or email: deposit@ccdc.cam.ac.uk].

\section{Acknowledgements}

Authors thank the Russian Foundation for Basic Research (Project No 02-03-32945) and Joint Project of the USA Civilian Research and Development Foundation and High Education of Russian Federation (Project BRHE REC-007) for the financial support.

\section{References and Footnotes}

1. Foster, R. Organic Charge-Transfer-Complexes; Academic Press: London-New York, 1960; p 33.

2. Kiselev, V. D.; Konovalov, A. I. Usp. Khim. 1989, 58, 383 [Russ. Chem. Rev. 1989, 58, 383 (Engl. Transl.)].

3. Konovalov, A. I.; Kiselev, V. D. Izv. Akad. Nauk, Ser. Khim. 2003, 52, 293 [Russ. Chem. Bull. Int. Ed. 2003, 52, 293].

4. Onishchenko, A. S. Dienovyi sintez [Diene Synthesis], Izdatelstvo AN SSSR, Moscow, 1963, 650 pp. (in Russian).

5. Kloetzel, M. C.; Herzog, H. L. J. Am. Chem. Soc. 1950, 72, 1991.

6. Jones, W. H.; Mangold, D.; Plieninger, H. Tetrahedron 1962, $18,267$.

7. Klarner, F.-G. ; Breitkopf, V. Eur. J. Org. Chem. 1999, 2757. 
8. Handbook of Chemistry and Physics, 75th Edn., Eds. Lide, D. R; Frederikse, H. P. R. CRC Press: Boca Raton, Ann Arbor-London-Tokyo, 1994-1995.

9. Cox, J. D.; Pilcher, G. Thermochemistry of Organic and Organometallic Compounds, Academic Press, London-New York, 1970; p 643.

10. Drljaca, A.; Hubbard, C. D.; Van Eldik, R.; Asano, T.; Basilevsky, M. A.; le Noble, W. J. Chem. Rev. 1998, 98, 2167.

11. Dinulescu, I. G.; Avram, M.; Nenitzescu, C. D. Chem. Ber. 1960, 93, 1795.

12. Kiselev, V. D.; Shakirov, I. M.; Konovalov, A. I. Zh. Org. Khim. 1984, 20, 1454 [J. Org. Chem. USSR 1984, 20, 1454 (Engl. Transl.)].

13. Kiselev, V. D.; Khuzyasheva, D. G.; Konovalov, A. I. Zh. Org. Khim. 1983, 19, 1268 [J. Org. Chem. USSR 1983, 19, 1268 (Engl. Transl.)].

14. Kiselev, V. D.; Kashaeva, E. A.; Potapova, L. N.; Iskhakova, G.G. Russ. Chem. Bull., Int. Ed. 2004, 53, 51.

15. van Eldik, R.; Hubbard, C. D.; Eds.; Chemistry under extreme or non-classical conditions; John Wiley and Spectrum Akademisher Verlag: 1997; p 168.

16. Altomare, A.; Cascarano, G.; Giacovazzo, C.; Viterbo, D. Acta Crystallogr. A 1991, 47, 744.

17. Straver, L.H.; Schierbeek, A. J. MOLEN. Structure Determination System; Nonius B.V.; Delft: The Netherlands, 1994; Vol. 1, p 2.

18. Spek, A. L. Acta Crystal. (A) 1990, 46, 34.

19. Weissberger, A. Organic solvents; Interscience: New-York, London, 1955; p 560. 